\title{
Nucleotratotomia trigeminal estereotáxica no tratamento da dor facial atípica
}

\author{
José Cláudio Marinho da Nóbrega*, Manoel Jacobsen Teixeira**, \\ Cláudio Fernandes Corrêa***, Massako Okada**** \\ Departamento de Neurologia da Faculdade de Medicina da Universidade de São Paulo
}

\section{RESUMO}

As características funcionais e morfológicas da face, aliadas à complexidade do fenômeno doloroso, tornam favorável a existência de inúmeras fontes de dor facial, como procuraram demonstrar as várias classificações existentes a respeito. A nucleotratotomia trigeminal consiste na ablação cirúrgica de núcleos trigeminais de segunda ordem e tratos.

Dois casos de dor facial atípica refratários ao tratamento medicamentoso ou a outras formas nãooperatórias são discutidos. A intensidade da dor pré e pós-operatória foi avaliada pela Escala Visual Analógica. A técnica operatória é descrita.

Os resultados imediatos foram satisfatórios em ambos os casos. Um doente teve recidiva da dor, com menor intensidade, dois meses após o procedimento e o outro estava assintomático oito meses depois. Um doente apresentou ataxia transitória que regrediu em dois meses; o outro teve meningite bacteriana no pós-operatório. Aspectos terapêuticos e as bases fisiopatológicas da indicação cirúrgica são apresentados.

\section{PALAVRAS-CHAVE}

Dor facial. Estereotaxia. Nucleotratotomia trigeminal.

\section{ABSTRACT}

Stereotactic trigeminal nucleotractotomy for treatment of atypical facial pain The functional and morphologic peculiarities of the face justify the occurrence of varied sources of pain. The trigeminal nucleotractotomy consists in a surgical lesion of secundary trigeminal nuclei and tracts.

Two cases of atypical facial pain refractory to clinical treatments are discussed. The intensity of pain was evaluated by the Visual Analogic Scale. The surgical technique is described.

The immediate results were satisfactory. One patient developed recurrent pain two months later and the other was asymptomatic for eight months. One patient presented transitory ataxia and the other developed bacterial meningitis.

The physiopathological basis of this procedure is discussed.

\section{KEYWORDS}

Facial pain. Stereotaxis. Stereotactic trigeminal nucleotractotomy.

\footnotetext{
* Neurocirurgião, estagiário do Serviço de Neurocirurgia Funcional do Instituto de Psiquiatria da Universidade de São Paulo.

** Professor-Doutor do Departamento de Neurologia da Faculdade de Medicina da Universidade de São Paulo.

*** Neurocirurgião e chefe da Clínica de Dor do Hospital Nove de Julho, São Paulo, SP.

**** Neurologista do Grupo Multidisciplinar de Dor do Departamento de Neurologia da Faculdade de Medicina da Universidade de São Paulo.
} 


\section{Introdução}

O termo neuralgia facial atípica foi criado por Frazier e Russe $l^{4} \mathrm{em} 1924$ para denominar a dor facial difusa, sem causa aparente e sem as características da neuralgia essencial do nervo trigêmeo e do glossofaríngeo.

Stookey e Ransohoff ${ }^{13}$, em 1959, classificaram a neuralgia facial atípica em duas categorias. Em uma, a dor é restrita à porção medial da face, região maxilar, frontal ao globo ocular, podendo sugerir neuralgia da divisão maxilar ou oftálmica. A região mandibular raramente é comprometida. Na segunda categoria, a dor localiza-se nas áreas de distribuição de outros nervos cranianos ou cervicais. Irradia-se para a região frontal, occipital, retromastóidea, cervical e, às vezes, para o ombro.

White e Sweet $^{21}$ classificaram, como neuralgia facial atípica, a dor facial constante e profunda não limitada ao território do nervo trigêmeo, com duração de horas, dias ou meses, ocorrendo sem fatores precipitantes, em doentes com tendência à dependência de drogas e com personalidade neurótica.

Em 1981, Cusik $^{3}$ conceituou como neuralgia facial atípica a dor facial vaga, com fisiopatologia desconhecida e com distribuição que não respeita o território de inervação dos nervos sensitivos da face. Law e Nelson ${ }^{9}$ descreveram-na como dolorimento, compressão, latejamento, repuxão, queimor e aperto difuso ou circunscrito. Intensifica-se com frio, fadiga, ansiedade e depressão. Pode acompanhar-se de lacrimejamento, rinorréia e hiperemia da face ${ }^{13}$. Costuma irradiar-se para as regiões retroauricular e cervical. Não há paroxismos. É contínua, dura horas ou dias. Raramente se instala ou desaparece subitamente ${ }^{22}$. Não apresenta fatores desencadeantes, como ocorre com a neuralgia essen$\mathrm{cial}^{8}$. Os doentes com dor facial atípica costumam apresentar traços neuróticos ${ }^{12}$.

Em 1988, a Sociedade Internacional de Cefaléias ${ }^{5}$ apresentou a classificação e os critérios diagnósticos das cefaléias, neuralgias cranianas e dor facial. Nela, 13 grupos foram catalogados. $\mathrm{O}$ grupo 11 é composto de cefaléia ou dor facial associada com patologias do crânio, pescoço, orelha, olhos, nariz, seios, dentes, boca, ou outras estruturas faciais ou cranianas. No grupo 12, encontram-se as neuralgias cranianas, dor de troncos nervosos e dor por desaferenciação. A partir disso, a dor facial persistente, que não tenha as características das neuralgias cranianas descritas e não esteja associada a sinais físicos ou a uma causa orgânica demonstrável, passou a ser denominada dor facial que não preenche os critérios dos grupos 11 e 12, em substituição ao termo dor facial atípica. Os critérios para diagnóstico desse tipo de dor são: a) caráter contínuo, persistindo na maior parte do dia ou o dia todo; b) é confinada, no início, a uma área limitada de uma hemiface. Pode ser irradiada para os maxilares superior ou inferior, ou para uma área mais ampla da face ou pescoço. É profunda e mal localizada; c) não é associada a perda sensitiva ou outros sinais físicos; d) investigações laboratoriais, incluindo radiografia da face e da mandíbula, não demonstram anormalidades relevantes.

Em 1937, Sjöqvist demonstrou que o trato espinhal do trigêmeo poderia ser seccionado por uma incisão na face posterolateral do bulbo, acima do nível do óbice. $\mathrm{O}$ procedimento usualmente resultava em analgesia térmica da face homolateral com preservação dos demais tipos de sensibilidade (apud Teixeira ${ }^{16}$ ).

Crue e cols. em 1967, Todd e cols. em 1969 e, em 1970, Hitchcok descreveram a tratototomia trigeminal estereotáxica e Fox, em 1973, a tratotomia percutânea à mão livre, procedimentos que se revelaram eficazes para o tratamento da dor facial por desaferenciação (apud Teixeira $^{17,18,20}$ ).

Schvarcz ${ }^{11}$, em 1971, denominou o procedimento de nucleotomia trigeminal para enfatizar a importância da lesão, principalmente dos neurônios de segunda ordem na via trigeminal.

Kanpolat e cols. ${ }^{6}$ desenvolveram a técnica de nucleotratotomia trigeminal guiada por tomografia computadorizada para dor facial por desaferenciação. Em nosso meio, Teixeira tem aplicado a técnica com sucesso (apud Schvarcz ${ }^{11}$ ).

Apresentam-se dois casos de doentes com dor facial atípica submetidos à nucleotratotomia trigeminal estereotáxica.

\section{Relato dos casos}

Caso 1: EAA, 42 anos de idade, sexo masculino, cor branca, procedente de Piracicaba, São Paulo, lingotador aposentado. Procurou o Ambulatório de Dor do Departamento de Neurologia do Hospital das Clínicas da Faculdade de Medicina da Universidade de São Paulo em março de 1997, relatando que, há 3 anos, iniciou-se, de maneira insidiosa, dor na região parietooccipital direita e que, no decorrer de semanas, localizou-se, em faixa, da região frontal à occipital, descrita como pontada, queimação, cortante, constante e com predomínio noturno. Não havia fatores de melhora, mas piorava com contato na face. Relatou que tinha feito uso de antiinflamatório não-hormonal sem melhora. Avaliado pela Escala Visual Analógica, deu escore 10. Ao exame neurológico, apresentava-se ansioso e hostil, sem outras anormalidades. Foram solicitados exames laboratoriais (hemograma, VHS, creatinina, glicose, líquido cefalorraquidiano com eletroforese de proteínas, T3, T4 e TSH), que foram 
normais. O paciente foi avaliado por um grupo multidisciplinar formado por odontólogo, otorrinolaringologista, fisiatra e psicólogo). Traços neuróticos foram diagnosticados na avaliação psicológica. A avaliação fisiátrica evidenciou pontos-gatilho nos músculos esplênio da cabeça e suboccipital, mas a inativação destes não resultou no desaparecimento da dor facial. O doente foi medicado com associação de naproxeno, clorpromazina e amitriptilina em doses crescentes, de acordo com a tolerância. Chegou-se a usar $150 \mathrm{mg}$ de amitriptilina e $100 \mathrm{mg}$ de clorpromazina. Não houve melhora da dor em um período de 11 meses, mantendose com valor 8 a 10 na Escala Visual Analógica. Em fevereiro de 1998, foi submetido à nucleotratotomia trigeminal estereotáxica. Evoluiu no pós-operatório com ataxia leve da marcha que desapareceu em dois meses. A dor teve melhora satisfatória inicialmente, ficando sem medicação; ao cabo de três meses teve recidiva da dor, sendo dado escore 4 na Escala Visual Analógica. Foi reintroduzida a medição inicial em doses menores. Na última avaliação, em novembro de 1999, estava usando amitriptilina $75 \mathrm{mg}$, associado a $20 \mathrm{mg}$ de clorpromazina ao dia. Aplicou escore 6 à dor.

Caso 2: PSM, 32 anos de idade, sexo masculino, cor branca, procedente de Morungaba, São Paulo, construtor civil, procurou o Ambulatório de Dor do Departamento de Neurologia do Hospital das Clínicas da Faculdade de Medicina da Universidade de São Paulo, em outubro de 1997, com queixa de dor na hemiface (fronte, região malar) direita, de início há três anos, de maneira insidiosa, referida em queimação, tensa, constante, que tinha predomínio noturno, piorava com emoções e melhorava quando estava trabalhando. Avaliado pela Escala Visual Analógica deu nota 10 à dor. Referia ter feito uso de antiinflamatório não-hormonal, sem melhora. Ao exame neurológico, apresentava-se consciente, lúcido, ansioso. Foram solicitados exames laboratoriais (hemograma, VHS, creatinina, glicose, líquido cefalorraquidiano com eletroforese de proteínas, $\mathrm{T} 3, \mathrm{~T} 4 \mathrm{e} \mathrm{TSH}$ ), que foram normais. O paciente foi avaliado pelo grupo multidisciplinar. A avaliação fisiátrica evidenciou pontos-gatilho no músculo pterigóideo direito. Foi realizada inativação destes, sem melhora da dor facial. O doente foi medicado com associação de naproxeno, clorpromazina e amitriptilina, com doses crescentes de acordo com a tolerância; chegou-se a usar $125 \mathrm{mg}$ de amitriptilina e $80 \mathrm{mg}$ de clorpromazina. Não houve melhora da dor na Escala Visual Analógica, mantendo-se entre 9 e 10 ao longo de dez meses. Submeteu-se a nucleotratotomia trigeminal estereotáxica em novembro de 1998. Não houve intercorrências e evoluiu com desaparecimento da dor. No quarto dia de pós-operátorio foi diagnosticada meningite bacteriana, que foi tratada apropriadamente. Manteve-se em acompanhamento e, em julho de 1999, começou a sentir dor pré-auricular direita, em peso, de leve intensidade avaliada como 3. Manteve-se sem medicação, pois referiu que a dor era suportável.

\section{Técnica cirúrgica}

A nucleotratotomia estereotáxica do trato espinhal do nervo trigêmeo é realizada sob anestesia local, com o doente na posição sentada ou deitada. Consiste na fixação do aparelho de estereotaxia de Hitchcock (Micromar-Diadema, São Paulo) ao segmento cefálico, seguida da realização de estereotomografia com fusão das imagens de atlas de estereotaxia com as da estereotomografia (Figura 1). O alvo estereotáxico é calculado e posicionado 4 a $6,5 \mathrm{~mm}$ lateralmente em relação à linha mediana, de acordo com a ocorrência da dor no território da terceira e da primeira divisões do nervo, respectivamente. Um eletródio de tungstênio é introduzido na transição occipitocervical e dirigido de baixo para cima e de fora para dentro, com inclinação de $20^{\circ}$ em relação aos planos transversal e sagital. O controle da penetração do eletródio na estrutura nervosa é realizado pela impedância tecidual. A localização é confirmada mediante estimulação monopolar de baixa voltagem, com estímulos de ondas quadradas de $5 \mathrm{~Hz}, 10 \mathrm{~Hz}, 50 \mathrm{~Hz}$ e $100 \mathrm{~Hz}$. No ponto em que a estimulação elétrica causar desconforto no local da dor referida, são realizadas lesões por radiofreqüência utilizando gerador Micromar (MicromarDiadema, São Paulo) ou Radionic modelo RFA-3 ${ }^{\mathrm{A}}$ (Radionic Inc - Burlington, Massachusetts, EUA), de modo a produzir coagulação com diâmetro de aproximadamente $2 \mathrm{~mm}^{18}$.

\section{Discussão}

A dor facial atípica é de difícil tratamento e não há medidas terapêuticas comprovadas. Desde que em pequena porcentagem de doentes, a dor facial atípica é manifestação de lesão estrutural tratável, devendo-se sempre procurar uma etiologia ${ }^{10}$.

Os antidepressivos proporcionam melhora em até $70 \%$ dos doentes com dor facial idiopática. Além de reduzir a intensidade da dor, a medicação reduz as alterações funcionais observadas em doentes, mesmo naqueles não deprimidos, com dor facial atípica ${ }^{19}$. A dor facial atípica pode ser aliviada com o emprego de antidepressivos e fenotiazínicos; os resultados, entretanto, são freqüentemente pouco gratificantes ${ }^{15}$. Se a 

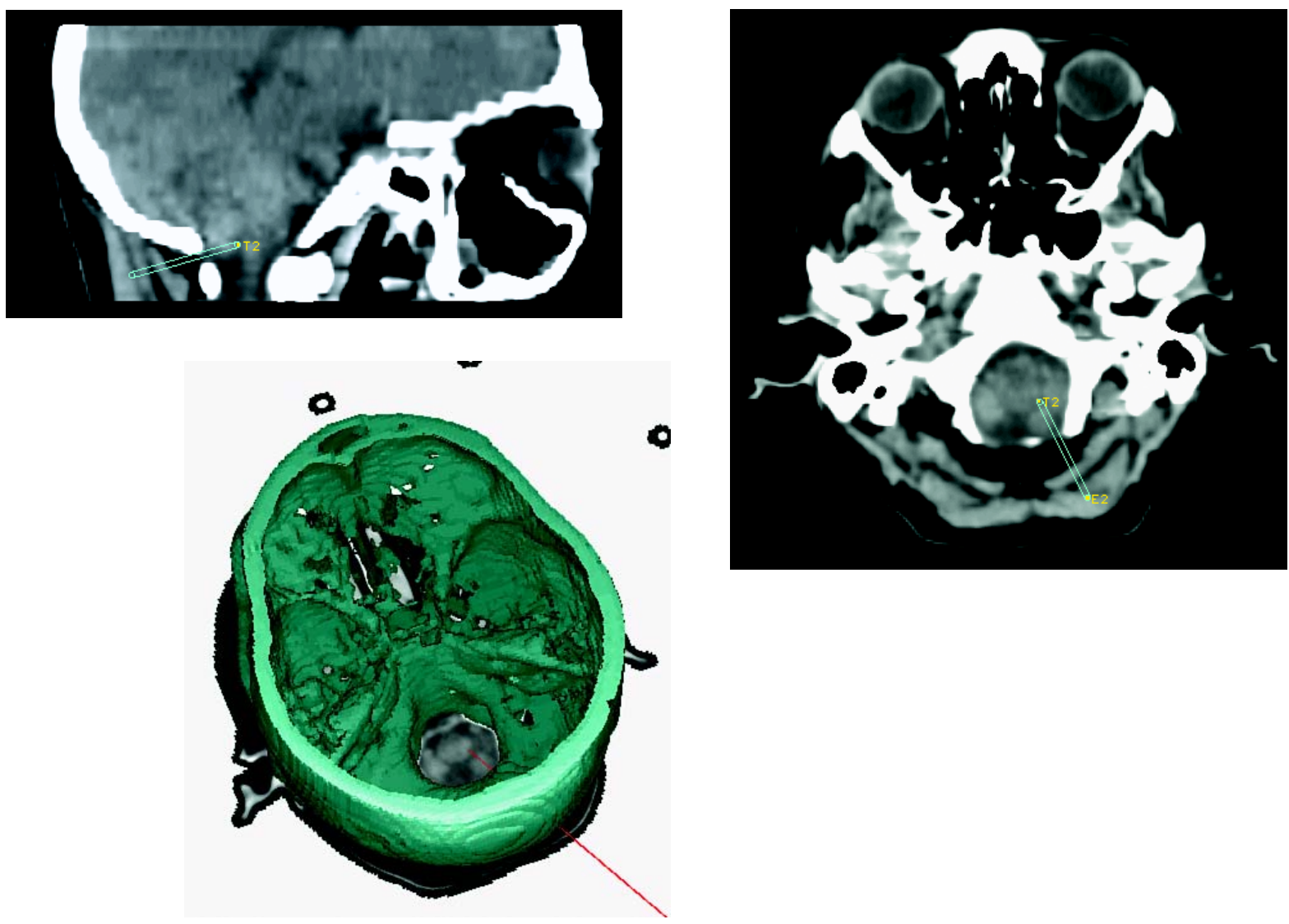

Figura 1 - Ilustração do trajeto de introdução do eletródio até o alvo.

dor tiver caráter constante ou em queimação, antidepressivos tricíclicos, tal como amitriptilina em doses variando de $75 \mathrm{mg}$ a $150 \mathrm{mg}$, associados a fenotiazínicos representam razoável opção terapêutica ${ }^{1}$. Os doentes foram medicados com amitriptilina até a dose máxima de $150 \mathrm{mg}$ em um e de $125 \mathrm{mg}$ em outro, sem melhora da intensidade da dor.

Os doentes com dor facial atípica costumam apresentar traços neuróticos ${ }^{12}$. $\mathrm{O}$ tratamento psiquiátrico também pode ser útil nesses casos ${ }^{15}$. Medidas psicoterápicas para dor facial atípica têm sido extensamente discutidas na literatura. Seguramente, se o doente tiver alterações psicopatológicas significativas em adição à dor facial atípica, o uso dessas medidas psicoterápicas é apropriado $^{10}$. Em um dos nossos doentes foram identificados traços neuróticos na avaliação psicológica.

Os procedimentos neurocirúrgicos antiálgicos estão indicados em casos nos quais os procedimentos farmacoterápicos, fisiátricos e os bloqueios anestésicos não proporcionam resultados satisfatórios ou associam-se a adversidades ${ }^{2,14,17}$.

Procedimentos percutâneos neuroablativos que podem ser realizados sob sedação são mais seguros que os a céu aberto. A realização de anestesia geral, muitas vezes necessária para a realização desses, pode colocar em risco a vida e a função dos doentes quando as condições clínicas e nutricionais estão comprometidas. Além disso, não permite a participação dos doentes na quantificação imediata dos resultados ${ }^{17,20}$.

A hiperatividade dos neurônios de segunda ordem nos núcleos trigeminais espinhais é uma possível causa para parestesias orofaciais constantes em pacientes com neuropatia trigeminal ou em dor facial mista, isto é, por nocicepção ou desaferenciação ${ }^{16}$. Kerr ${ }^{7}$ defende a destruição desses neurônios em humanos no tratamento da dor facial neuropática. Baseando-nos no conceito de que a sensibilização dos núcleos trigeminais é componente importante para a ocorrência da dor facial atípica, podemos inferir que a nucleotratotomia trigeminal é um procedimento adequado no seu tratamento.

Os resultados imediatos foram satisfatórios em ambos os casos. Durante o período de acompanhamento, o caso 1 apresentou recidiva da dor, com menor intensidade, em três meses, avaliada com nota 4 na escala adotada, sendo reintroduzida a medicação. $\mathrm{O}$ caso 2 manteve-se assintomático por oito meses, quando começou a sentir dor pré-auricular, em peso, quantificada com nota 3 na escala.

Hitch $\operatorname{cock}^{16}$ relatou um caso de dor facial atípica tratada por nucleotratotomia trigeminal sem melhora 
inicial, nem durante o acompanhamento de sete meses. Loeser ${ }^{10}$ encontrou poucos relatos da eficácia da tratotomia trigeminal e outras lesões neuroablativas do mesencéfalo, do tálamo e do tronco cerebral.

As complicações gerais observadas são mais numerosas com a nucleotratotomia trigeminal a céu aberto, destacando-se os acidentes vasculares encefálicos, infartos do miocárdio, infecções respiratórias e das vias urinárias, meningites, septicemias, lesão dos núcleos e tratos dos funículos posteriores e incontinência urinária. Isso sugere que o procedimento percutâneo seja mais seguro, principalmente quando indicado em doentes idosos ou debilitados ${ }^{16,18,20}$. Entre os nossos doentes, um teve meningite bacteriana diagnosticada e tratada precocemente e outro apresentou leve ataxia transitória da marcha, complicação que se deve à lesão do corpo restiforme.

\section{Conclusão}

A indicação da nucleotratotomia trigeminal no tratamento da dor facial atípica é fundamentada no fato de haver hiperatividade neuronal nos neurônios de segunda ordem das vias trigeminais. É uma opção terapêutica útil, às custas de baixa morbidade nos casos em que os procedimentos farmacoterápicos, fisiátricos e psicológicos não proporcionam resultados satisfatórios.

\section{Referências}

1. BURCHIEL KJ, BURGESS JA: Differential diagnosis and manangement of orofacial pain. In Tolisson CD, Satterthwaite JR, Tolisson JW (ed): Handbook of Pain management. Ed 2. Philadelphia, Willians \& Wilkins, 1994, cap 22, pp 280-93.

2. CORREA CF, TEIXEIRA MJ: Tratamento neurocirúrgico para dor oncológica. In Arquivos do $4^{\circ}$ Simbidor, 1999, São Paulo, p 301.

3. CUSIK JF: Atypical trigeminal neuralgia. JAMA 245:2328-9, 1981.

4. FRAZIER CH, RUSSEL EC: Neuralgia of the face. Arch Neurol Psychiatry (Chicago) 11:557-63, 1924.

5. HEADACHE CLASSIFICATION COMMITTE OF THE INTERNATIONAL HEADACHE SOCIETY: Classification and diagnostic criteria for headache disorders, cranial neuralgias and facial pain. Cephalalgia 8:196, 1988.
6. KANPOLAT Y, DEDA H, AKYAR S: CT-guided trigeminal nucleotomy. Acta Neurochir (Wien) 100:1124, 1989.

7. KERR FWL: Spinal $V^{\text {th }}$ nucleolysis. Intractable craniofacial pain. Surg Forum 17: 419-21, 1966.

8. KIRK EJ: Impulses in dorsal spinal nerve rootlets in cats and rabbits arising from dorsal ganglia isolated from the periphery. J Comp Neurol 155:165-76, 1974.

9. LAW WR, NELSON ER: Internal carotid aneurysm as a cause of Reader's paratrigeminal syndrome. Neurology (Chicago) 18: 43-6, 1968.

10. LOESER JD: Cranial neuralgias. In Bonica JJ, Loeser JD, Chapman CR, Fordyce WE (ed): The management of pain. Ed 2. Philadelphia, Lea \& Febiger, 1994, vol 1, cap 38, pp 684-5.

11. SCHVARCZ JR: Stereotactic trigeminal nucleotomy for dysesthetic facial pain. Stereotact Funct Neurosurg 68:175-81, 1997.

12. SPECULAND B: Intractable facial pain and illnesss behavior. Pain 11:213-9, 1981.

13. STOOKEY B, RANSOHOFF J: Trigeminal neuralgia its history and treatment. Springfield, Charles C Thomas Publisher, 1959.

14. TEIXEIRA MJ: Tratamento neurocirúrgico da dor. Rev Med 76:78-82, 1997.

15. TEIXEIRA MJ: Critérios de dor facial típica. In Anais do $3^{\circ}$ Simpósio Internacional de Dor, 1997, São Paulo, p 19.

16. TEIXEIRA MJ: Various functional procedures for pain. In Gildemberg PL, Tasker R (ed): Textbook of estereotaxis and functional neurosurgery. New York, 1998, cap 140, pp 1390-402.

17. TEIXEIRA MJ: Tratamento neurocirúrgico da dor neuropática. Rev Med 78:305-36, 1999.

18. TEIXEIRA MJ: Tratotomia de Lissauer e lesão do corno posterior da medula espinhal. In Arquivos do $4^{\circ}$ Simbidor, 1999, São Paulo, pp 213-5.

19. TEIXEIRA MJ: Os antidepressivos no tratamento da dor facial. In Arquivos do $4^{\circ}$ Simbidor, 1999, São Paulo, p 281

20. TEIXEIRA MJ, YENG LT, SOUZA EC, PEREIRA VC: A lesão do trato de Lissauer e do corno posterior da medula espinhal e a estimulação do sistema nervoso central para o tratamento da neuralgia pós-herpética. Arq Bras Neurocir 18:17-36, 1999.

21. WHITE JC, SWEET WH: Pain and the neurosurgeon. Springfield, Charles C Thomas Publisher, 1959.

22. YONAS $\mathrm{H}$, JANNETTA PJ: Neurinoma of trigeminal root and atypical trigeminal neuralgia. Neurosurgery 6:273-7, 1987.

Original recebido em outubro de 1999

Aceito para publicação em junho de 2000

\section{Endereço para correspondência:}

José Cláudio Marinho da Nóbrega

Av. 11 de Junho, 940, ap. 13

CEP 04041-003 - São Paulo, SP 